Roy: Editor-in-Chiefs Note

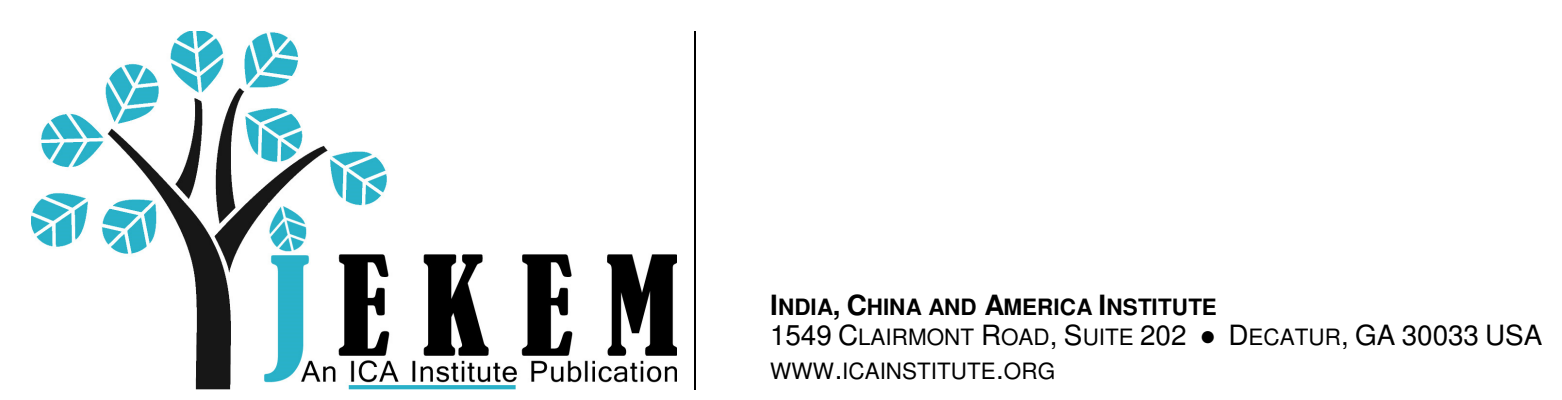

Editor-in-Bhiefs Note

Ashok K. Roy

Volume
November 2010

Published by DigitalCommons@Kennesaw State University, 2010 


\title{
Editor-in-Ghiefs Note
}

\author{
Ashok K. Roy \\ Kennesaw State University \\ Editor-in-Chief, \\ Journal of Emerging Knowledge on Emerging Markets
}

Journal of Emerging Knowledge on Emerging Markets

Volume 2

November 2010

$\mathrm{A}$

year ago, the Journal of Emerging Knowledge on Emerging Markets (JEKEM) published its first issue. The world was a different place; time, we can neither start nor stop, but only steer. The pursuit of knowledge, much like history, is a broadly connected process and an aggregate of desires. We trust that the articles in this edition of JEKEM will, in their own modest way, serve as a timely, well-directed locomotive of knowledge.

In this issue, many remarkable conversations have been chronicled for the public square across a broad swatch and living tapestry of topics. The eclectic mix of authors has examined concepts, looked at regions, and expressed thoughts. In reviewing manuscripts, we continue, as always, to pose the essential question: "What is its value to our readership?" The result is, I believe, insights, often profound, from a diverse group of authors. In this issue, the authors are a mix of young scholars and professionals and seasoned academics, who provide a spate of methodological approaches and analytic perspectives to contemporary issues. The contents reflect topics in area studies, application of fractals, land ownership in rural areas, and a host of other relevant issues. In combination, this set of working papers contributes to the timely working knowledge base of the diverse readership that characterizes JEKEM's professional target audience. 
I am especially grateful to members of the Editorial Board for taking time from their busy lives to read manuscripts and provide helpful comments. At the same time, it would be remiss of me not to thank Dr. Jagdish Sheth for inviting me to engage in one of the best jobs in academic publication. At critical times, Dr. Sheth shepherded me with his infectious enthusiasm.

A succession of talented researchers assisted me. I was extremely lucky to work with the remarkable Prashant Das who gave generously of his time and talent. My greatest thanks are to Roxanne Russell. I have relied on Roxanne's signature combination of intellectual sophistication and professional savvy. I marvel at her dedication, insight, diligence, and skillful editorship.

I want to take a moment to mention the new logo or crest of the Journal. The tree in the crest symbolizes the spread of learning, light, and the growth of knowledge.

In addition, to increase the reach of the Journal we have hosted it on Digital Commons which is powered by the Berkeley Electronic Press and is a platform that is used by universities. Works hosted on the Digital Commons are listed in Google Scholar, as well.

Earlier this year I visited India and China seeing first-hand the emergence of a new economic order from what was once clearly the Third World to their arrival on the world stage. Just a few decades ago, outsiders saw India and China as places where nothing ever changes. Today, both countries have become the most dynamic regions on earth, marking strategic geo-political shifts regionally and internationally. In political and economic circles today, when a model of economic development is discussed, the "China model" presents an appealing option. At its core, however, the "China model" is the same export-oriented East Asian development model, albeit on a much grander scale. On my return from China, I wrote about my impressions regarding China's action-oriented public policy, which took it from a mist-shrouded country to the world's most dynamic economy today in little more than a generation. My thoughts were published in the "China Daily" on June 24, 2010. Academics often make the "what-if" game worthy of discourse, although generally by the term "counterfactual." In this direction, I want to comment on University of Chicago professor and Nobel Laureate Robert Fogel's article published earlier this year in which he predicted that in just thirty years from now China's economy will be bigger than the U.S. economy. While Dr. Fogel presents a persuasive case, scholars such as Dr. Minxin Pei see many banana peels on China's epic road to be the world's superpower economy.

We are pleased to give hospitality to divergent ideas to keep our readership informed and help navigate the fog and cacophony of knowledge. 